\title{
Barrel Cortex Microcircuits: Thalamocortical Feedforward Inhibition in Spiny Stellate Cells Is Mediated by a Small Number of Fast-Spiking Interneurons
}

\author{
Qian-Quan Sun, John R. Huguenard, and David A. Prince \\ Department of Neurology and Neurological Sciences, Stanford School of Medicine, Stanford, California 94305
}

\begin{abstract}
Inhibitory and excitatory neurons located in rodent barrel cortex are known to form functional circuits mediating vibrissal sensation. Excitatory neurons located in a single barrel greatly outnumber interneurons, and form extensive reciprocal excitatory synaptic contacts. Inhibitory and excitatory networks must interact to shape information ascending to cortex. The details of these interactions, however, have not been completely explored. Using paired intracellular recordings, we studied the properties of synaptic connections between spiny neurons (i.e., spiny stellate and pyramidal cells) and interneurons, as well as integration of thalamocortical (TC) input, in layer IV barrels of rat thalamocortical slices. Results show the following: (1) the strength of unitary excitatory connections of spiny neurons is similar among different targets; (2) although inhibition from regular-spiking nonpyramidal interneurons to spiny neurons is comparable in strength to excitatory connections, inhibition mediated by fast-spiking (FS) interneurons is 10 times more powerful; (3) TC EPSPs elicit reliable and precisely timed action potentials in FS neurons; and (4) a small number of FS neurons mediate thalamocortical feedforward inhibition in each spiny neuron and can powerfully shunt TC-mediated excitation. The ready activation of FS cells by TC inputs, coupled with powerful feedforward inhibition from these neurons, would profoundly influence sensory processing and constrain runaway excitation in vivo.
\end{abstract}

Key words: somatosensory cortex; fast-spiking interneuron; IPSPs; spiny stellate neuron; thalamocortical; feedforward inhibition

\section{Introduction}

Rodent whisker sensory input is represented somatotopically in the barrel field of layer IV of S1 neocortex (Woolsey and Van der Loos, 1970). A cohort of morphologically distinct excitatory neurons and inhibitory interneurons exist in layer IV barrels (Woolsey and Van der Loos, 1970; Keller and White, 1987). Excitatory neurons located in a barrel form extensive synaptic interconnections (Feldmeyer et al., 1999; Schubert et al., 2003). Different subtypes of inhibitory neurons in barrel cortex are also known to form inhibitory networks coupled by both electrical and chemical synapses (Gibson et al., 1999; Beierlein et al., 2000, 2003). The total number of excitatory neurons within a barrel structure is 5-10 times that of inhibitory cells (Woolsey et al., 1975; Simons and Woolsey, 1979; White and Rock, 1980; White and Peters, 1993; White et al., 1993; Micheva and Beaulieu, 1995), and it is proposed that GABAergic inhibition shapes the responses of cortical neurons and constrains runaway excitation (Nelson, 1991; Vidyasagar et al., 1996).

Received Feb. 27, 2004; revised Nov. 21, 2005; accepted Nov. 22, 2005.

This work was supported by National Institutes of Health Grants NS06477 and NS12151 from the National Institute of Neurological Disorders and Stroke, and the Pimley Research and Training Funds. We are grateful to Isabel Parada for excellent technical assistance with immunocytochemistry.

Correspondence should be addressed to Dr. David A. Prince, Department of Neurology and Neurological Sciences, Stanford University School of Medicine, Stanford, CA 94305. E-mail: daprince@stanford.edu.

Q.-Q. Sun's present address: Zoology and Physiology, 1000 East University Avenue, Department 3166, Laramie, WY 82071.

DOI:10.1523/JNEUROSCI.4727-04.2006

Copyright $\odot 2006$ Society for Neuroscience $\quad$ 0270-6474/06/261219-12\$15.00/0
Both excitatory and inhibitory neurons in barrel cortex are activated by thalamocortical (TC) inputs (Simons, 1978; Agmon and Connors, 1991, 1992; Kim et al., 1995; Castro-Alamancos and Connors, 1997; Porter et al., 2001; Beierlein et al., 2003). In barrel cortex, disynaptic feedforward inhibition, mediated by direct thalamocortical excitation of interneurons, is a critical part of the sensory gating process (Agmon and Connors, 1991; Agmon et al., 1996; Porter et al., 2001; Swadlow, 2002, 2003). There is both synchronous activation of populations of glutamatergic neurons by thalamocortical afferents and abundant coupling among these excitatory neurons that could potentially lead to aberrant recurrent excitation and prevent precise detection of subsequent sensory inputs. We hypothesized that strong and reliable feedforward inhibition onto excitatory neurons in layer IV must be present to effectively "shunt" recurrent excitation and preserve discrete signaling in cortical networks.

In addition, intrabarrel inhibition likely plays an important role in activity-dependent plasticity that underlies fundamental aspects of circuit maturation, such as sensory-mediated refinement of receptive fields (Egger et al., 1999; Feldman et al., 1999; Froemke and Dan, 2002; Nelson et al., 2002). Experiencedependent synaptic plasticity in sensory cortex requires precision in spike timing of the postsynaptic excitatory cortical neurons, which could be compromised by the abundant recurrent excitation between excitatory neurons. Studies obtained from barrel cortex in vivo suggest that subgroups of interneurons, presumably fast-spiking interneurons, known as suspected interneurons (SINs), are a major candidate for providing the feedforward in- 
hibition (Swadlow, 2002, 2003). However, direct experimental evidence for thalamocortical feedforward inhibition onto excitatory neurons, mediated by identified interneurons, is lacking.

Using paired recording techniques in thalamocortical slices, we examined interactions between synaptically connected excitatory and inhibitory neurons in layer IV of barrel cortex. We found that (1) basket cells form very extensive local axonal arborizations within a single barrel, (2) the strength of unitary inhibitory connections from fast-spiking basket cells is much greater than that of excitatory local connections, and (3) fast-spiking interneurons can be reliably and precisely activated by thalamocortical inputs and provide feedforward inhibition onto excitatory neurons.

\section{Materials and Methods}

Brain slice preparations. Young Sprague Dawley rats (3-5 weeks postnatal) were deeply anesthetized with pentobarbital sodium $(55 \mathrm{mg} / \mathrm{kg})$ and decapitated. The brains were quickly removed and placed into cold $\left(\sim 4^{\circ} \mathrm{C}\right)$ oxygenated slicing medium containing the following (in $\mathrm{mm}$ ): $2.5 \mathrm{KCl}, 1.25 \mathrm{NaH}_{2} \mathrm{PO}_{4}, 10.0 \mathrm{MgCl}_{2}, 0.5 \mathrm{CaCl}_{2}, 26.0 \mathrm{NaHCO}_{3}, 11.0$ glucose, and 234.0 sucrose. Thalamocortical slices were prepared according to methods described by Agmon and Connors (1991, 1992). Tissue slices (300-400 $\mu \mathrm{m})$ were cut using a vibratome (TPI, St. Louis, MO), transferred to a holding chamber, and incubated $\left(35^{\circ} \mathrm{C}\right)$ for at least $1 \mathrm{~h}$ before recording. Individual slices were then transferred to a recording chamber fixed to a modified microscope stage, and allowed to equilibrate for at least $30 \mathrm{~min}$ before recording. Slices were minimally submerged and continuously superfused with oxygenated physiological saline at the rate of $4.0 \mathrm{ml} / \mathrm{min}$. The physiological perfusion solution contained the following (in mM): $126.0 \mathrm{NaCl}, 2.5 \mathrm{KCl}, 1.25 \mathrm{NaH}_{2} \mathrm{PO}_{4}, 1.0 \mathrm{MgCl}_{2}, 2.0$ $\mathrm{CaCl}_{2}, 26.0 \mathrm{NaHCO}_{3}$, and 10.0 glucose. Solutions were gassed with $95 \%$ $\mathrm{O}_{2} / 5 \% \mathrm{CO}_{2}$ to a final $\mathrm{pH}$ of 7.4 at a temperature of $35 \pm 1^{\circ} \mathrm{C}$.

Dual whole-cell patch-clamp recording from identified neurons in the barrel. The method for identification of the barrel subfield in living thalamocortical slices has been described in previous studies (Agmon and Connors, 1992; Feldmeyer et al., 1999, 2002; Petersen and Sakmann, $2000)$. A low-power objective $(2.5 \times)$ was used to identify barrels and thalamic nuclei, and a high-power water immersion objective $(40 \times)$ with Nomarski optics and infrared video was used to visualize individual neurons. Recording pipettes were fabricated from capillary glass obtained from World Precision Instruments (Sarasota, FL) (M1B150F-4), using a Sutter Instrument (Novato, CA) P80 puller, and had tip resistances of 2-5 $\mathrm{M} \Omega$ when filled with the intracellular solutions below. A Multiclamp 700A amplifier (Molecular Devices, Foster City, CA) was used for voltage-clamp and current-clamp recordings from pairs of neurons. Patch pipette saline was modified according to Brecht and Sakmann (2002) and was composed of the following (in $\mathrm{mm}$ ): 70 K-gluconate, $30 \mathrm{KCl}, 10.0$ phosphocreatine-Tris, $3.0 \mathrm{MgCl}_{2}, 0.07 \mathrm{CaCl}_{2}$, 4 EGTA, 10.0 HEPES, $4.0 \mathrm{Na}_{2}$-ATP, and 1.0 Na-GTP, pH adjusted to 7.4 and osmolarity adjusted to $280 \mathrm{mOsm}$. This high $\left[\mathrm{Cl}^{-}\right]_{\mathrm{i}}$ pipette solution was used to increase the driving force for $\mathrm{GABA}_{\mathrm{A}}$ receptor-dependent responses and increase their detection. Under these conditions, IPSPs were depolarizing. To assess functional inhibition, some experiments (see Figs. 9, 10) were performed with pipettes containing a lower, more physiological level $(6 \mathrm{~mm})$ of $\left[\mathrm{Cl}^{-}\right]_{\mathrm{i}}$ containing only K-gluconate with no KCl. Neurobiotin (0.5\%; Vector Laboratories, Burlingame, CA) was regularly added to the patch pipette solution. Data were accepted for analysis when access resistance in whole-cell recordings ranged from 4 to $12 \mathrm{M} \Omega$, and was stable ( $<25 \%$ change) during the recording. Current and voltage protocols were generated using pClamp8 software (Molecular Devices).

A sharpened bipolar tungsten electrode, placed in the internal capsule or thalamic relay nuclei, was used to activate thalamocortical afferents (Agmon and Connors, 1991, 1992). Monosynaptic EPSPs or EPSCs were evoked in fast-spiking (FS) interneurons or spiny neurons with TC stimuli. (The term "spiny neurons" is used here to refer to both spiny stellate and pyramidal cells.) The stimulus intensity was gradually increased until all-or-none EPSCs were evoked and then increased further to obtain maximal amplitude responses. In some slices, the extracellular bipolar electrode was positioned closer to the internal capsule or striatum (caudate/putamen) to obtain an optimal TC response. The approximate position of the stimulating electrode was within the TC projections, as estimated from the results of $\mathrm{Di}\left[\operatorname{diI}\left(1,1^{\prime}\right.\right.$, dioctadecyl-3,3,3' $3^{\prime}$ tetramethylindocarbocyanine perchlorate)] applications reported by others (Agmon and Connors, 1991; Agmon et al., 1995). Near-threshold firing frequency was defined as the action potential (AP) discharge rate induced by an intracellular DC current pulse $30 \mathrm{pA}$ above threshold for inducing firing. PSP latency is the time from presynaptic AP peak to peak postsynaptic PSP, whereas AP latency is the time from either the onset of an intracellular current pulse or an extracellular fiber stimulation to the peak of the evoked AP. Cross-correlations were calculated with Clampfit 8.0.

Histological processing and anatomical reconstruction. After recording, brain slices were fixed in $100 \mathrm{~mm}$ phosphate-buffered (PB) solution, $\mathrm{pH}$ 7.4, containing $1 \%$ paraformaldehyde and $2.5 \%$ glutaraldehyde at $4^{\circ} \mathrm{C}$ for at least $24 \mathrm{~h}$. Endogenous peroxidase was blocked by incubation of the slices in $1 \% \mathrm{H}_{2} \mathrm{O}_{2}$ for $15-20 \mathrm{~min}$. After several rinses in $\mathrm{PB}$ solution, they were then transferred to $1 \%$ avidin-biotinylated horseradish peroxidase complex containing $0.1 \%$ Triton X-100 in PB (0.1 M; pH 7.4) (ABC-Elite Camon, Wiesbaden, Germany) and left overnight at $4^{\circ} \mathrm{C}$ while being shaken lightly. The next day, slices were reacted using 3,3diaminobenzidine (DAB) (Sigma, St. Louis, MO) and $0.01 \% \mathrm{H}_{2} \mathrm{O}_{2}$ until dendrites and axonal arbors were clearly visible $(\sim 2-5 \mathrm{~min})$. Slices were mounted on glass slides, embedded in DPX-mounting media (Aldrich, Milwaukee, WI), and coverslipped.

To identify the barrel structure in layer IV of the somatosensory cortex, cytochrome oxidase staining according to Wong-Riley (1979) was used. In brief, brain slices were stored overnight in $4 \%$ paraformaldehyde at $4^{\circ} \mathrm{C}$. After several rinses in PB solution, they were resectioned at 100 $\mu \mathrm{m}$, and sections were incubated in a PB solution containing $50 \mathrm{mg}$ of $\mathrm{DAB}, 15-30 \mathrm{mg}$ of cytochrome $c$, and $20 \mathrm{mg}$ of catalase $/ 100 \mathrm{ml}$ at $37^{\circ} \mathrm{C}$ for $2 \mathrm{~h}$ in the dark. The reaction was stopped when individual barrels were clearly distinguishable from the background. After several rinses in PB solution, sections were mounted on glass slides, air-dried, defatted in absolute alcohol and xylene, embedded in DPX-mounting media (Aldrich), and coverslipped.

Neuronal three-dimensional reconstruction and morphometric measurements of dendritic and axonal arbors were made with Neurolucida software (MicroBrightField, Colchester, VT). Cells and their processes were drawn with a camera lucida using 40 or $100 \times$ objectives. Biocytin histochemistry often resulted in background staining that allowed delineation of cortical laminae and barrel borders. In some slices, cytochrome oxidase histochemistry and labeling of single biocytin-filled neurons were combined to reveal the dendritic and axonal organization with respect to the barrel structure.

\section{Results}

\section{Morphology of rat barrel cortex neurons}

Interneurons and excitatory neurons located in layer IV barrels were examined electrophysiologically in this study. Of 240 neurons studied, 60 were reconstructed and morphologically identified, including 28 star pyramidal neurons, 13 spiny stellate (SS) cells, and 19 interneurons. Spiny stellate cells and star pyramidal neurons are characterized by high density of dendritic spines (data not shown) (Woolsey et al., 1975; White and Rock, 1980; Schubert et al., 2003). Spiny stellate cells differ from star pyramids in that they do not have apical dendrites that extend beyond the border of barrels up to the pia (Fig. 1) (Feldmeyer et al., 1999; Schubert et al., 2003). Reconstruction under low magnification revealed that somata of different cell types had different patterns of localization with respect to the barrel structure. Spiny stellate cells tended to be found in the lower half of layer IV and near the border of barrel walls, whereas star pyramidal neurons were dispersed throughout the barrel (Fig. 1, bottom left inset) (Simons and Woolsey, 1979; Simons et al., 1984). Interneurons, with 


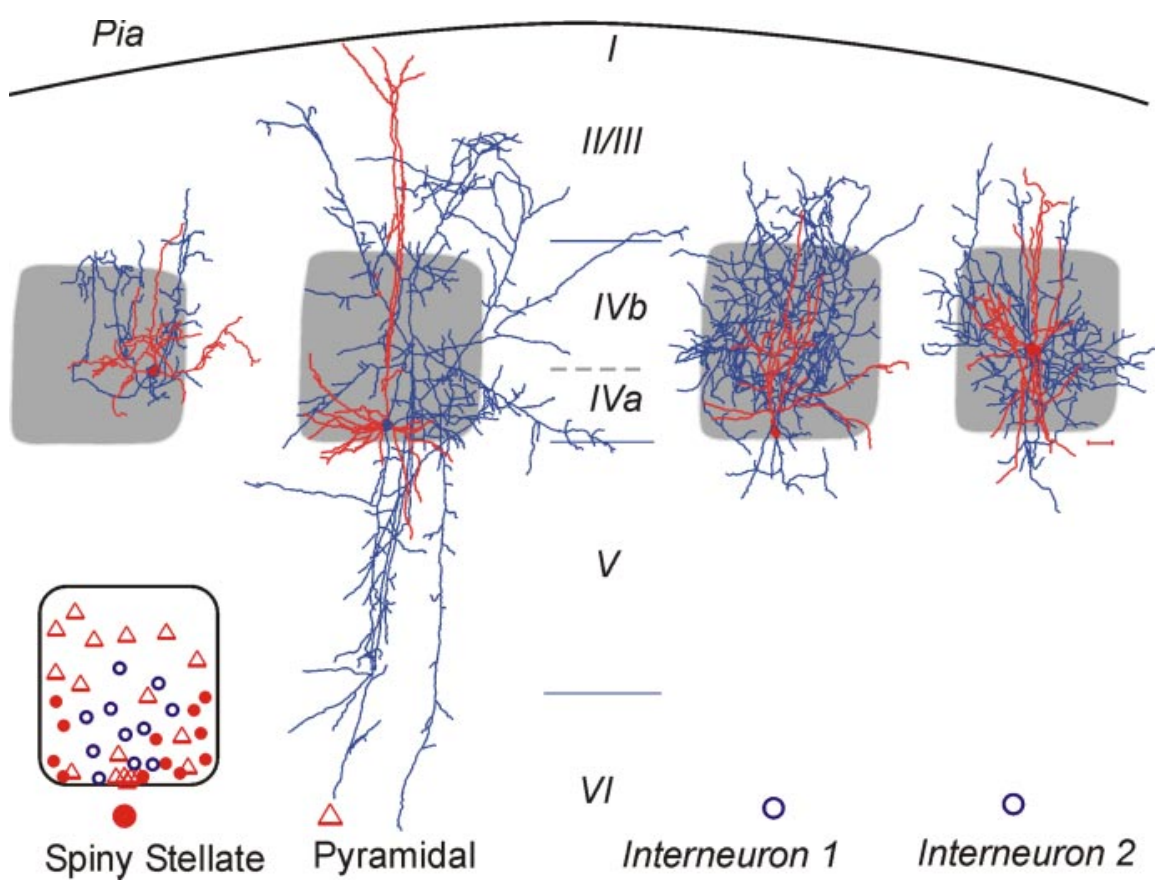

Figure 1. Camera lucida reconstruction of four types of neurons included in this study. Red, Dendrites and somata; blue, axons; gray shading, barrel structure. Scale bar near interneuron 2, $100 \mu \mathrm{m}$ for all panels. Bottom left inset shows localization of cell bodies within barrel structures: spiny stellate cells (filled red circles), star pyramidal neurons (red open triangles), and basket cells (open blue circles). I-VI, Cortical laminae. Pial surface, Curved line at top of figure.

Table 1. Synaptically connected neuronal pairs in layer IV of somatosensory cortex

\begin{tabular}{|c|c|c|c|c|}
\hline Neuron 1 & Neuron 2 & $\begin{array}{l}\text { Connections } \\
\text { (forward, reverse) }\end{array}$ & $\begin{array}{l}\text { Reciprocal } \\
\text { connections }\end{array}$ & $\begin{array}{l}\text { Connection } \\
\text { probability }\end{array}$ \\
\hline Spiny stellate & FS & 4,8 & $2\}$ & $\mathrm{e} \Theta, 9 / 70(12.9 \%)$ \\
\hline Star pyramidal & FS & 5,7 & 1) & $i, \mathrm{e}, 15 / 70(21.4 \%)$ \\
\hline Spiny stellate & RSNP & 3,2 & 1) & $\mathrm{e} \Theta, \mathrm{i}, 5 / 15(33.3 \%)$ \\
\hline Star pyramid & RSNP & 2,2 & 1) & $i \ominus, e, 4 / 15(26.7 \%)$ \\
\hline Spiny stellate & Star pyramid & 2,3 & $0\}$ & $\mathrm{e} \Theta, \mathrm{e}, 5 / 24(20.8 \%)$ \\
\hline Spiny stellate & Spiny stellate & 2 & $1\}$ & \\
\hline
\end{tabular}

Connections are physiologically identified synaptic connections. Neuron 1 was presynaptic for forward connection and postsynaptic for reverse connections. Connection probability was determined based on electrophysiological phenotype, which was similar for all spiny cells. In many cases, multiple paired recordings could be obtained with a single presynaptic cell. The only requirement for unambiguous identification of the presynaptic cell type was a synaptic connection in one of these pairs. Not all neurons were recovered for histochemical staining. Therefore, spiny (excitatory) cells are grouped together for this analysis. e $\Theta i$ indicates a forward connection from an excitatory to an inhibitory cell, whereas $i \ominus \mathrm{e}$ is the reverse connection, and $\mathrm{e} \Theta \mathrm{e}$ is a connection between spiny cells.

smooth or sparsely spiny dendrites, were located around the lower center barrel region (Fig. 1, bottom left inset).

Different interneuron subtypes have been described in layer IV (Simons, 1978; Keller and White, 1987; Agmon and Connors, 1992; Kim et al., 1995; Castro-Alamancos and Connors, 1997; Beierlein et al., 2000; Porter et al., 2001; Wang et al., 2002). We mainly focused on the morphological aspects of interneurons with FS (see below) physiological properties. These FS interneurons all tended to have a local axonal plexus (Fig. 1, right two cells). All 11 FS interneurons had axons that were almost completely contained within the barrel (Fig. 1), but there was variability in their axonal and somatodendritic morphologies. Four FS interneurons had smaller somata (mean area, $150 \pm 35 \mu \mathrm{m}^{2} ; n=$ 4 ), and dendrites that arose at either multiple points from the soma or from a main dendrite, and were oriented toward the upper portion of the barrel, rarely extending beyond the barrel border (Fig. 1, second cell from right). The axonal plexus of these small FS neurons had a large number of short segments that branched extensively. Seven FS interneurons had large and round somata (mean area, $320 \pm 45 \mu \mathrm{m}^{2}$ ) and dendrites that radiated in all directions, with a predominance of vertically oriented ones, giving these cells a bitufted appearance (Fig. 1, rightmost cell). The axon plexus of these large FS neurons had fewer, but longer segments. All of these large and small interneurons had a fast-spiking firing pattern and formed synaptic contacts around somata and proximal dendrites of spiny neurons (see Fig. 5A). They were thus presumably subclasses of basket cells (Martin et al., 1983; Keller and White, 1987; Hendry et al., 1989; Tamas et al., 1997; Wang et al., 2002) and are collectively termed FS interneurons below.

\section{Unitary inhibitory synaptic potentials evoked in spiny cells by FS cells are significantly larger than reciprocal unitary excitatory potentials}

Dual whole-cell patch-clamp recordings were obtained from 120 neuronal pairs in layer IV barrels. Of these, 50 pairs were synaptically connected, and 40 had both somata located within layer IV barrels (Table 1). Interneurons and excitatory cells were distinguished according to (1) their dendritic structures (Fig. 1 and results above), (2) firing properties during current injections (Fig. 2A2) (Gupta et al., 2000; Wang et al., 2002), and (3) the GABAergic or glutamatergic nature of the unitary synaptic connection made by the neuron. The latter was routinely verified by estimating the reversal potential of the synaptic response and/or demonstrating sensitivity to $10 \mu \mathrm{M}$ CNQX (see Fig. 6A2) or 10 $\mu \mathrm{M}$ gabazine. Under our experimental conditions (see Materials and Methods), IPSPs were depolarizing but could be distinguished by their reversal potential near $-30 \mathrm{mV}$, which was distinct from the EPSP reversal potential near $0 \mathrm{mV}$. In contrast to spiny cells that fired adapting, low-frequency $(15.7 \pm 1.3 \mathrm{~Hz} ; n=$ 11) spike trains (Fig. $2 A 2 b$ ), FS interneurons had a mean nearthreshold steady firing frequency of $63 \pm 22 \mathrm{~Hz}$ (Fig. 2A2a) $(n=$ 11), maximum firing rate of $>200 \mathrm{~Hz}$, and virtually no spike frequency adaptation (Wang et al., 2002; Beierlein et al., 2003).

Synaptic connections were examined initially under current clamp by repeatedly eliciting short trains of APs alternately in presumed presynaptic and postsynaptic neurons (Fig. 2 B1). Synaptic connections were then confirmed by evoking $>100$ single action potentials at $1 \mathrm{~Hz}$ with brief depolarizing current pulses in presynaptic neurons (Fig. 2B2). Both unitary EPSPs (uEPSPs) and unitary IPSPs (uIPSPs) had short, fixed latencies (Figs. 2 B2, $3 A 1,5 B 1$ ). As shown in Figure $2 B$ and Table 2, uIPSPs and uEPSPs were readily distinguishable in current-clamp recordings by their decay time constant, which was much longer for uIPSPs (see below). In most experiments, postsynaptic responses were also examined under voltage clamp (Figs. 3A3, 6A2).

Fifteen pairs were identified in which a GABAergic FS interneuron was presynaptic to an anatomically identified spiny (glutamatergic) stellate or pyramidal neuron (Figs. 2 B1, left, 3A1, 5; Table 1). Three of the 15 FS-SS or FS-pyramidal neuronal pairs 
were reciprocally connected (Fig. $2 \mathrm{B1}$, Table 1). In 8 of 15 pairs, the postsynaptic excitatory neuron was identified as a spiny stellate cell (Figs. 1, 5A; Table 1) and in 7 as a star pyramidal neuron. In 9 of the 50 total pairs, excitatory connections from spiny neurons onto FS interneurons were identified (Fig. 2B; Tables 1, 2), including 3 pairs that were reciprocally connected (Fig. 2B; Tables 1,2). Four of the 9 presynaptic excitatory neurons were of SS in type, and 5 were star pyramidal cells (Tables 1,2 ).

The properties of uIPSPs from FS onto spiny neurons were quite different from those of uEPSPs from spiny neurons onto FS cells. The amplitude of uIPSPs was approximately four times larger than that of uEPSPs $(6.1 \pm 1.3 \mathrm{mV}$ for uIPSPs vs $1.1 \pm$ $0.4 \mathrm{mV}$ for uEPSPs; $p<0.001$ ) (Fig. $2 B$ ) and the decay time constant $\left(\tau_{\text {decay }}\right)$ was approximately four times longer for uIPSPs than for uEPSPs $(p<0.05)$ (Table 2$)$. In voltage-clamp recordings, the peak conductance of uIPSCs in spiny neurons $(5.6 \pm 1.4 \mathrm{nS} ; n=5)$ was $\sim 10$ times greater than for uEPSPs in interneurons $(0.56 \pm 0.2 \mathrm{nS} ; n=6)($ Fig. $3 A 3, B)(p<$ $0.001)$.

The inhibitory connections were also more reliable. The coefficient of variation (CV) for uIPSP amplitude was significantly smaller than that for uEPSPs (Table $2, p<0.05$ ), while the failure rates were 4 and $11 \%$ for uIPSPs and uEPSPs, respectively. However, no significant differences were found in latency from spike to peak PSP $(2.0 \pm 0.3$ and $1.5 \pm 0.2 \mathrm{~ms}$ for IPSPs and uEPSPs, respectively) or in rise time $\left(\tau_{\text {rise }}\right)$, suggesting that both uIPSPs and uEPSPs included in this study are probably generated close to the somatic site of recording. These results show that inhibition from single FS interneurons onto excitatory cells is far stronger than the unitary excitation that FS interneurons receive from single local excitatory neurons. This may be attributable in large part to a larger number of inhibitory versus excitatory synaptic contacts per pair. Our anatomical reconstructions of close axonal-dendritic appositions (compare Figs. 4A, 5A) support this conclusion, as do previous reports (Tamas et al., 1997; Feldmeyer et al., 1999; Wang et al., 2002).

Regular-spiking nonpyramidal (RSNP) interneurons provide weak local inhibition onto spiny neurons

Four interneurons that did not have fast-spiking firing properties were also found to have functional synaptic contacts with SS or pyramidal neurons. These interneurons had firing properties similar to those described previously for RSNP interneurons of layer IV barrel cortex (Agmon and Connors, 1992; Zhu and Connors, 1999; Porter et al., 2001). The near-threshold firing frequency for these four presynaptic neurons was $15 \pm 4 \mathrm{~Hz}$. In two
2
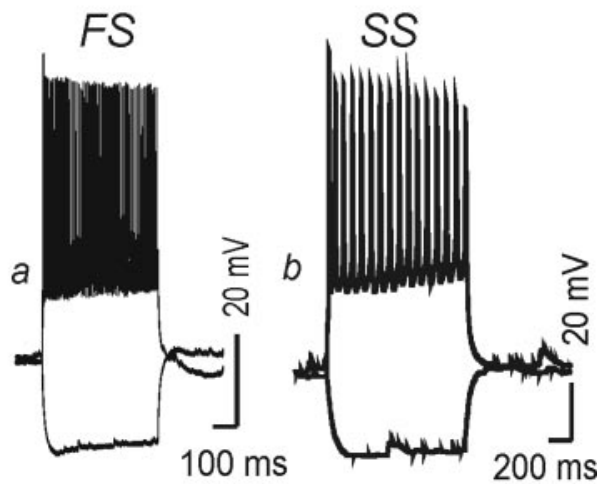

B1 Reciprocal chemical connection 2

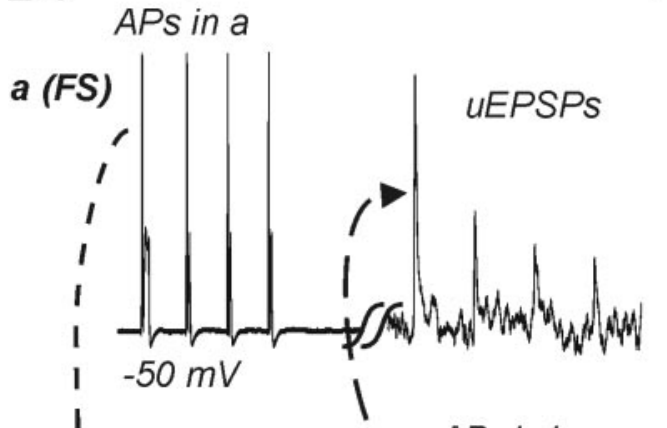

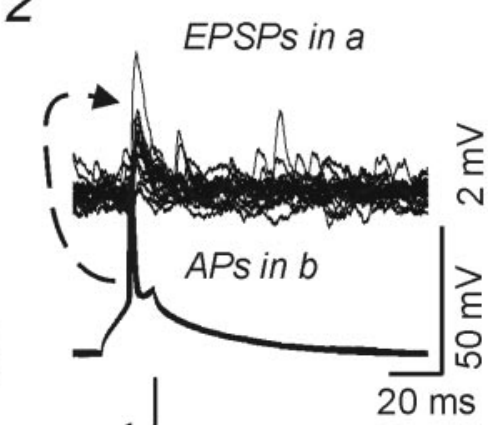

APs in a

Figure 2. Recordings form reciprocally connected spiny stellate cell and fast-spiking interneuron in layer IV barrel. A1, Lowmagnification image of the barrel field in a thalamocortical slice, with pial surface to the right. Dashed circles indicate individual barrels. a, b, Recording patch pipettes within a barrel near the layer V border. P, Local perfusion electrode. A2, B, Current-clamp recordings. $\mathbf{A 2}$, Responses evoked by current steps ( -100 and $+200 \mathrm{pA}$ ) in fast-spiking interneuron (a) and regular-spiking spiny stellate cell (b). $\boldsymbol{B}$, Paired recordings from a reciprocally connected fast-spiking cell (a) (FS) and spiny stellate cell (b) (SS) show unitary synaptic potentials elicited by trains $(\boldsymbol{B} 1)$ or single action potentials $(\boldsymbol{B} 2)$ in the presynaptic cell. $\boldsymbol{B} 1$, Trains of APs elicited by depolarizing currents ( $250 \mathrm{pA} ; 100 \mathrm{~ms}$ ) in cell a (top left) evoked uIPSPs in cell b (bottom left, dotted line and arrow), whereas action potentials in cell b (bottom right, dashed line and arrow) elicited uEPSPs in cell a (top left). B2, Top, Single APs in cell b evoked uEPSPs in cell a (top panel, 15 traces overlaid). B2, Bottom, Single APs in cell a evoked uIPSPs in cell b (15 traces overlaid). Calibrations in bottom right panel for traces showing APs; calibrations in bottom left panel for traces showing uPSPs.

of the four pairs, reciprocal connections were present between the RSNP interneuron and an SS cell (Fig. 6, Table 1). Compared with uIPSPs from FS neurons, the UIPSPs from RSNP interneurons onto spiny cells were smaller (peak amplitude, $0.8 \pm 0.3$ $\mathrm{mV}$ ) (compare Figs. 6 B1, 2B). The uIPSPs of the RSNP interneurons also showed weak paired-pulse facilitation, suggesting that the inhibitory synapses of RSNP interneurons had different properties with respect to short-term plasticity than those of the uIPSPs from FS interneurons (compare Figs. 633 , bottom; $2 B 1$, left). Other properties of RSNP uIPSPs, such as decay time constant (Fig. 6 B2) and rise time, were similar to uIPSPs of FS interneurons (data not shown). The uEPSPs in RSNP interneurons 
A1

2

Current-clamp in FS and SS

uIPSPs in SS neuron (30 $\mathrm{mM}[\mathrm{Cl}])$

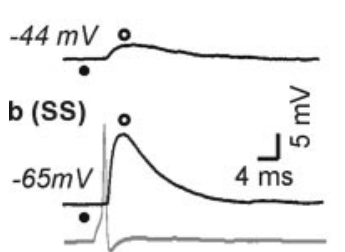

a (FS)

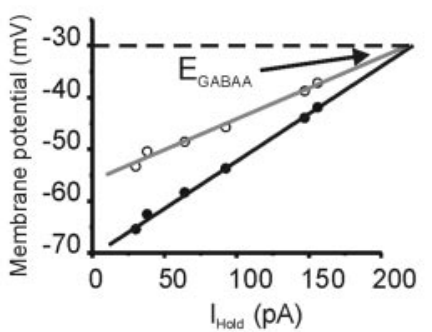

$B$

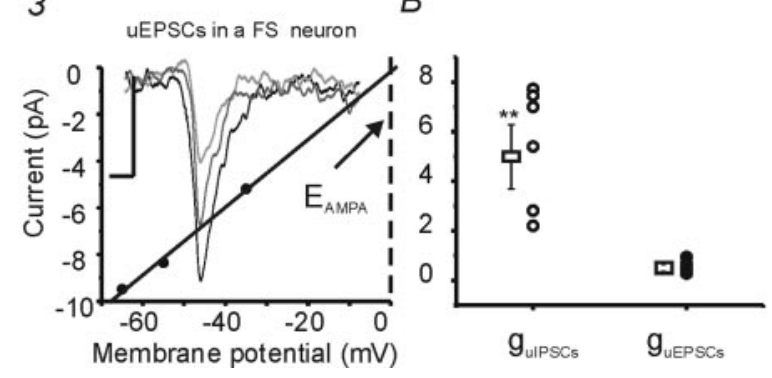

Figure 3. The conductance of FS-spiny cell ulPSPs is $\sim 10$ times larger than spiny-FS cell uEPSCs. A1, Current-clamp recording of presynaptic action potentials (bottom gray trace) in an FS neuron (a), and postsynaptic uIPSPs in an SS neuron (b). $V_{m}$ of the $S S$ neuron was varied between -44 and $-65 \mathrm{mV}$ with DC current injection. Open circles, Time of peak ulPSP amplitude. Filled circles, $V_{m}$ before synaptic activation. $\boldsymbol{A} 2$, Relationship between holding current and resulting $V_{m}$ values at rest (filled circles) and at the peak of uIPSPs (open circles). Black solid line, Linear regression fitting for data shown in filled black circles (baseline before IPSP). Gray solid line, Linear regression fit for data shown in open circles (at peak of IPSP). The conductance for $G A B A_{A}-$ mediated uIPSPs, estimated from the difference of the two linear fits, is $3 \mathrm{nS}$. Dashed line indicates $G A B A_{A}$ reversal potential estimated from the intersection of the two linear fits. $\mathbf{A 3}$, $I-V$ relationship for uEPSCS in a spiny neuron. Solid line, Linear regression fit, giving an estimated uEPSC conductance of $0.25 \mathrm{nS}(p<0.05 ; r=0.99)$. Dashed line, Estimated reversal potential for AMPA-mediated response (near $0 \mathrm{mV}$ ). Inset, Representative traces showing averaged uEPSCs recorded at different holding potentials $(-65,-55$, and $-35 \mathrm{mV})$ in a FS neuron. Calibration: $2 \mathrm{~ms}, 1 \mathrm{pA}$. $\boldsymbol{B}$, Conductances of ulPSCs ( $\mathrm{g}_{\text {ulPscs, }}$ open circles, $n=7$ ) and uEPSCS ( $g_{\text {uepscs }}$ filled circles, $n=6$ ) in spiny neurons. Open squares, Mean uPSCs. ${ }^{* *} p<0.01$.

were not different from those onto FS interneurons or excitatory neurons (compare Fig. 6A1,B1, top graph, with Fig. 2 B; Table 3).

\section{Strength of uEPSPs is similar among different postsynaptic targets in layer IV barrels}

We also examined uEPSPs between layer IV excitatory neurons in seven excitatory-excitatory pairs (Tables 1,3 ). Three unitary excitatory connections were between star pyramidal neurons, two were between spiny stellate cells, and two involved a spiny stellate and star pyramidal neuron. Each pair of synaptically coupled neurons was within the same barrel structure (Fig. $4 A, B$, right). uEPSCs were not found in eight simultaneous recordings from pairs of excitatory neurons located in two adjacent barrels (Fig. $4 B$, left; $C 1$ ) (see also Feldmeyer et al., 1999). Three-dimensional reconstruction of the pyramidal neurons showed that their dendritic arbors were distributed, for the most part, within a single

Table 2. Comparison of properties of uEPSPs from either SS or pyramidal cells onto FS neurons and uIPSPs from FS cells onto spiny neurons in layer IV of somatosensory cortex

\begin{tabular}{lccccc}
\hline Type of connections & Conductance $(\mathrm{nS})$ & $\tau_{\text {rise }}(\mathrm{ms})$ & $\tau_{\text {decay }}(\mathrm{ms})$ & CV & No. of pairs \\
\hline FS-SS (ulPSPs) & $5.6 \pm 1.4^{* * *}$ & $2.0 \pm 0.3$ & $37 \pm 11^{*}$ & $0.4 \pm 0.1^{*}$ & 15 \\
Spiny-FS (uEPSPs) & $0.56 \pm 0.2$ & $1.5 \pm 0.2$ & $10.6 \pm 2.0$ & $0.6 \pm 0.1$ & 9 \\
\hline
\end{tabular}

CV, Coefficient of variation for uEPSP amplitude.

${ }^{*} p<0.05,{ }^{* * *} p<0.001$ compared with uEPSPS.

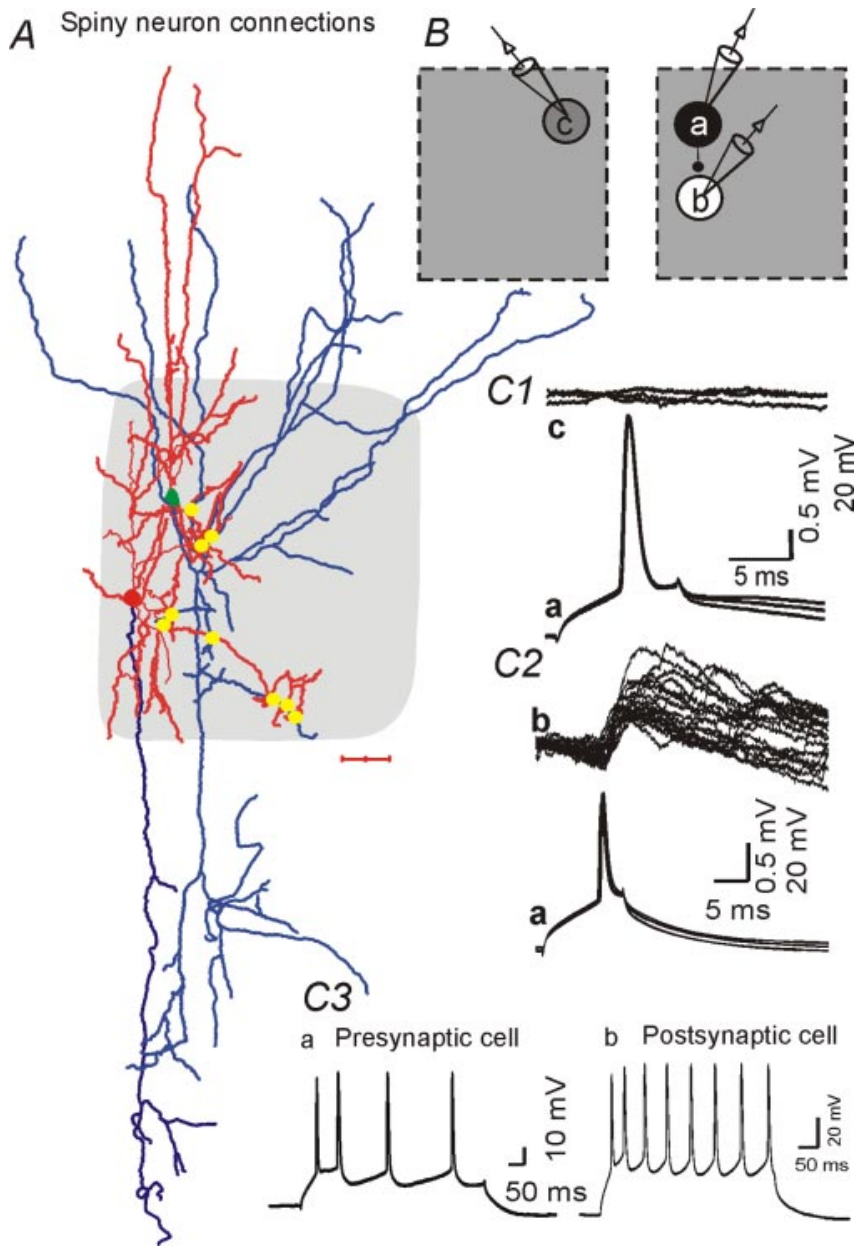

Figure 4. Synaptic connections between star pyramidal neurons located in the same barrel. $A$, Camera lucida reconstruction of a synaptically connected pair of star pyramidal neurons. Red, Dendrites; blue, axons. Gray shading, Barrel structure. Scale bar, $100 \mu \mathrm{m}$. Yellow dots indicate putative contacts between axons of presynaptic cell (green soma) and dendrites of postsynaptic cell (red soma) as identified from $100 \times$ microscopic images. $\boldsymbol{B}$, Positions of cells whose recordings are shown in C. Star pyramidal neuron (a) forms synaptic contact with another star pyramidal neuron (b) located in the same barrel, but not with another spiny star pyramidal neuron (c) located in the adjacent barrel (not shown in A). C1, Presynaptic APs in cell a (bottom trace, 3 sweeps overlaid) do not evoke a synaptic response in cell c (top sweeps). C2, APs in cell a (bottom, 20 traces overlaid) evoked uEPSPs in cell b (top). C3, Typical AP trains, evoked by 100 $\mathrm{pA}, 0.5 \mathrm{~s}$ depolarizing current pulses in cell $\mathrm{a}$ and cell $b$, show frequency adaptation.

column and their axons also projected mainly vertically within the same column (Figs. 1, 4A). However, a small fraction of the axons also projected to adjacent barrel columns (Figs. 1, 4A). Interestingly, the putative sites of connections formed by three star pyramidal neuronal pairs, as judged by close axonal-dendritic appositions, were all exclusively located within layer IV, although the dendritic arbors of the postsynaptic pyramidal neurons extended beyond layer IV (Fig. 4A). The amplitudes of uEPSPs in excitatory neurons were similar to those in FS interneurons (compare Figs. 4C2, $2 \mathrm{~B}$, top panels; Table 3). There were no significant differences in amplitude (mean or CV), $\tau_{\text {rise }}$, or $\tau_{\text {decay }}$ for uEPSPs between excitatory neuronal pairs and those between excitatory cells and FS interneurons (Fig. 6B1-B3, Table 3), although the mean amplitude of uEPSPs onto interneurons (RSNP and FS) tended to be larger (Table 3). 

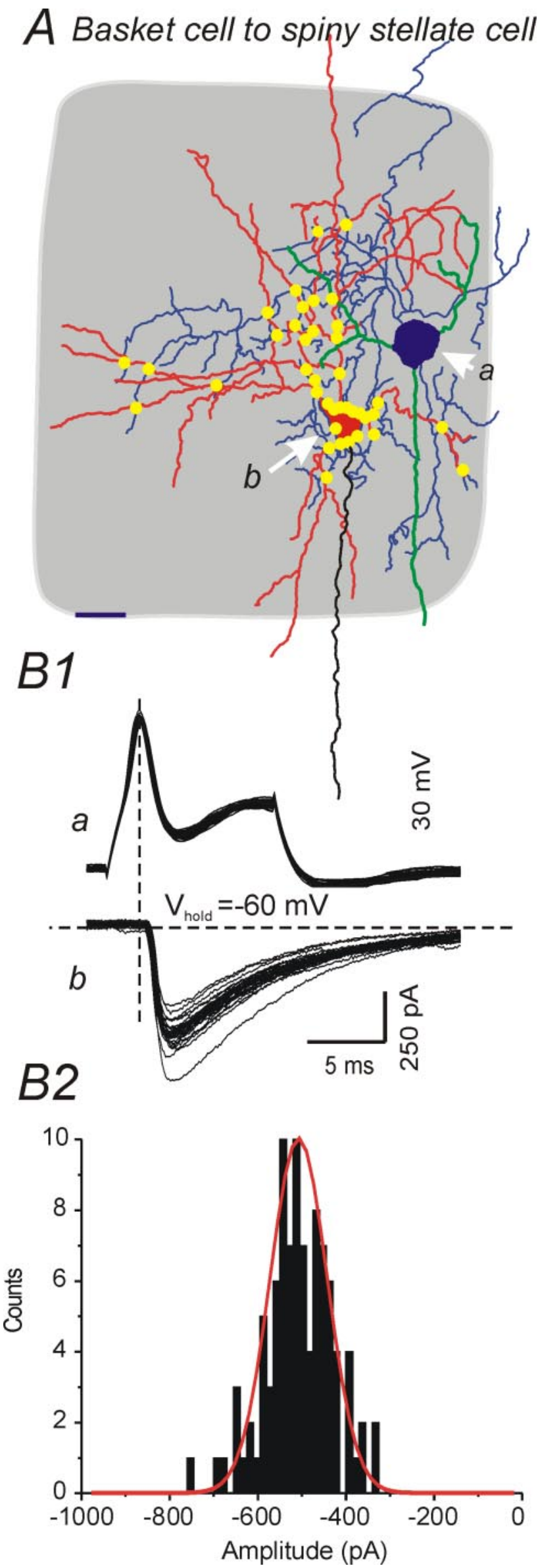

In summary, these results suggest that local unitary excitatory synapses from spiny neurons are similar among different targets (FS, RSNP interneurons, spiny stellate neurons, and star pyramidal neurons) and that the uIPSPs from FS interneurons are far more powerful than those from RSNP interneurons or uEPSPs from spiny cells. Therefore, FS interneurons are likely to be the major source of local inhibitory control in layer IV barrels, and the uIPSPs of even single FS cells are potentially sufficient to overcome local cortical excitatory connections, depending on convergent summation rules (Somogyi et al., 1998)

\section{Thalamocortical excitation of fast-spiking interneurons}

We observed that TC-evoked EPSPs in FS neurons had a larger amplitude, smaller $\mathrm{CV}$, and lower failure rate, and were more likely to trigger action potentials than those in spiny cells (data not shown) (see also Gil et al., 1999; Beierlein et al., 2002; Beierlein et al., 2003). Results of in vivo studies suggest that TC excitation can elicit highly synchronized spikes in interneurons (Bruno and Simons, 2002; Swadlow, 2002, 2003). We therefore examined the mechanisms underlying the TC-mediated synchronization of FS interneuronal discharges in vitro. As expected, the ability of a given thalamocortical EPSP to trigger action potentials in an FS interneuron was dependent on the resting membrane potential $\left(V_{\mathrm{m}}\right)$ (Fig. 7A1). Although the probability of evoking a spike varied with resting potential, all suprathreshold TC stimuli evoked precisely timed APs over a wide range of $V_{\mathrm{m}}$ values (approximately -45 to $-60 \mathrm{mV} ; n=6$ ) (Fig. $7 B 2$, inset, TC). These precisely timed action potentials in FS interneurons would lead to network synchrony, as previously reported in vivo (Swadlow, 2002, 2003) and in vitro (Gil et al., 1999; Beierlein and Connors, 2002). In contrast, APs elicited by direct depolarizing current application from different resting potentials showed significant timing variations (Fig. 7B2). These results are consistent with those obtained in vivo and suggest that FS cells can be reliably and precisely activated by thalamocortical inputs. In contrast, thalamocortical stimulation evoked poorly timed APs in SS neurons (see Fig. 10B1) $(n=20)$ and RSNP neurons (data not shown $)(n=5)$.

\section{Unitary disynaptic thalamocortical feedforward inhibition from FS interneurons onto spiny neurons}

To examine the roles of TC-mediated feedforward inhibition onto excitatory neurons, we made recordings from three pairs of synaptically connected FS-spiny neurons, in which TC connections were intact onto each cell. As in other experiments, uIPSPs were recorded using a pipette solution containing a high intracellular $\mathrm{Cl}^{-}$concentration $(30 \mathrm{~mm})$. This resulted in an increase in $\mathrm{Cl}^{-}$driving force and depolarizing IPSPs that allowed for accurate determination of IPSP onset (Gupta et al., 2000; Wang et al., 2002). Single APs in FS neurons elicited reliable and robust fixedlatency depolarizing uIPSPs in spiny neurons (Figs. 2 B2, bottom; $8 A 3)$. The latency from the peak of the presynaptic AP to the peak

$\leftarrow$

Figure 5. Unitary inhibitory responses mediated by a fast-spiking basket cell. $\boldsymbol{A}$, Camera lucida reconstruction of a synaptically connected fast-spiking basket cell (a, blue cell body and axon, green dendrites)-spiny stellate neuron (b, red cell body and dendrites, black axon) pair. Gray shading, Barrel structure. Scale bar, $20 \mu \mathrm{m}$. Yellow dots indicate putative contacts between axons of presynaptic fast-spiking cell and dendrites of postsynaptic spiny stellate cell as identified from $100 \times$ microscopic images. B1, Unitary synaptic currents elicited by directly evoked single APs in the presynaptic FS cell. Top trace, APs in FS cell; bottom trace, ulPSCs in spiny stellate cell. $V_{\text {hold }}=-60 \mathrm{mV} . B 2$, Histogram showing amplitude distribution of ulPSCs in $B 1$. The solid red line indicates a Gaussian fit to the uIPSC amplitude distribution. 
uEPSPs in RSNP

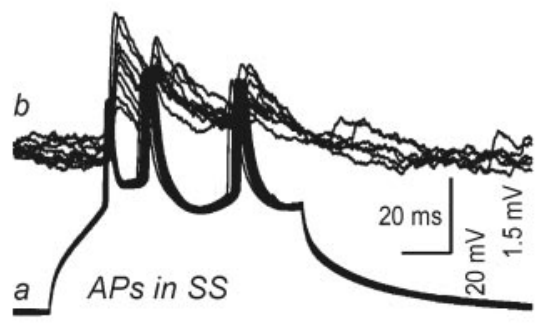

A2 Voltage-clamp $\left(V_{\text {Hold }}=-70 \mathrm{mV}\right)$

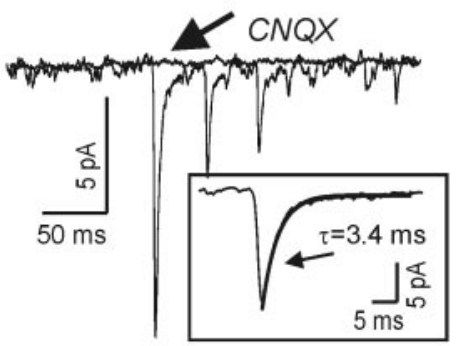

B2
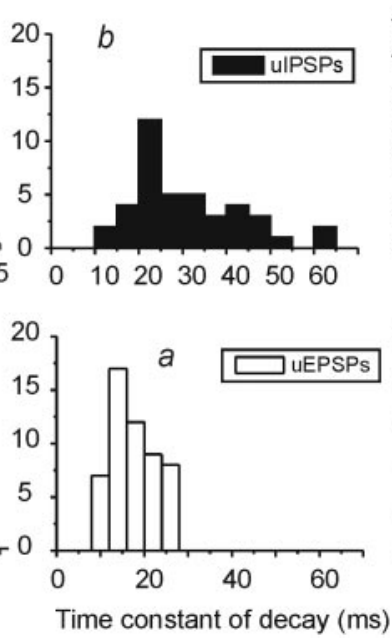

Current-clamp (+ CNQX)

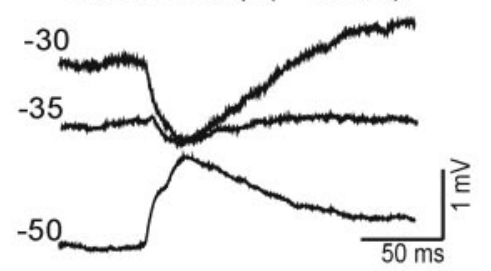

B3

Inter-pulse interval $200 \mathrm{~ms}$

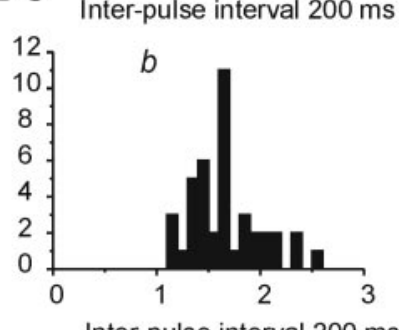

Inter-pulse interval $200 \mathrm{~ms}$

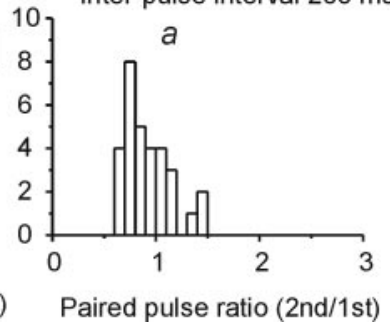

Figure 6. Reciprocal connections between spiny neurons and regular spiking (RSNP) interneurons. A1, Depolarizing current pulses (300 pA; $150 \mathrm{~ms}$ ) evoke trains of three APs in SS cell a (bottom) and trains of three uEPSPs in RSNP cell b (top panel, 30 traces superimposed). A2, Voltage-clamp recording of uEPSCs in RSNP cell b evoked as in $\mathbf{A 3}$ under control conditions, and in the presence of CNQX, which abolished the uEPSCs (arrow). Inset, Averaged initial uEPSC of 30 trains with overlaid single exponential fit for decay phase (solid gray line; $\tau=3.4 \mathrm{~ms} ; V_{\text {hold }}=-70 \mathrm{mV}$ ). $\boldsymbol{A}$, Depolarizing current pulses ( $300 \mathrm{pA} ; 150 \mathrm{~ms}$ ) evoke trains of four APs in RSNP cell a (bottom) and depolarizing uIPSPs in RSNP cell b (top). $\boldsymbol{A 4}$, Current-clamp recording of ulPSPs at indicated $V_{\mathrm{m}}$ values in the presence of CNQX. $\boldsymbol{B}$, Histograms showing distributions of amplitude $(\boldsymbol{B} 1)$, decay time constant $\left(\tau_{\mathrm{D}}\right)(\boldsymbol{B} 2)$, and paired-pulse ratio (at 200 ms interval) ( $B 3$ ) for uEPSPs in RSNP cell a of $\boldsymbol{A} \boldsymbol{1}$ (open bars, top graphs) and ulPSPs in an SS cell a of $\boldsymbol{A 3}$ (black bars, bottom graphs). $E_{\mathrm{Cl}}=-32 \mathrm{mV}$ in $\boldsymbol{A} \mathbf{3}$ and $\boldsymbol{A 4}$.

Table 3. Comparison of properties of uEPSPs from either SS or pyramidal cells onto glutamatergic neurons and interneurons in layer IV of somatosensory cortex

\begin{tabular}{llllll}
\hline Postsynaptic neuron & Amplitude $(\mathrm{mV})$ & $\tau_{\text {rise }}(\mathrm{ms})$ & $\tau_{\text {decay }}(\mathrm{ms})$ & CV & No. of pairs \\
\hline FS interneurons & $1.1 \pm 0.4$ & $1.5 \pm 0.2$ & $10.6 \pm 2.0$ & $0.6 \pm 0.1$ & 9 \\
Spiny (SS or pyramidal) & $0.7 \pm 0.2$ & $1.3 \pm 0.1$ & $11.5 \pm 0.6$ & $0.6 \pm 0.1$ & 7 \\
RSNP interneurons & $1.0 \pm 0.3$ & $1.7 \pm 0.5$ & $12.3 \pm 2.4$ & $0.5 \pm 0.3$ & 5
\end{tabular}

CV, Coefficient of variation for uEPSP amplitude. No statistically significant difference between the any two groups was found for any parameter.

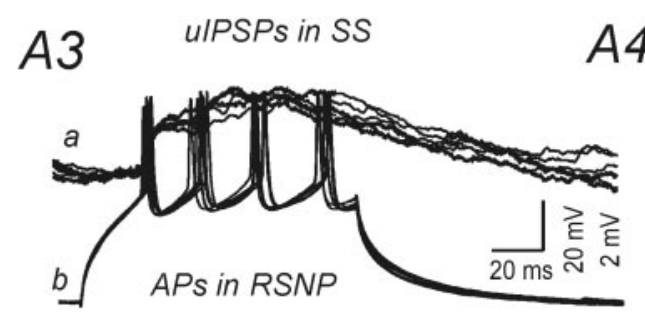

B1
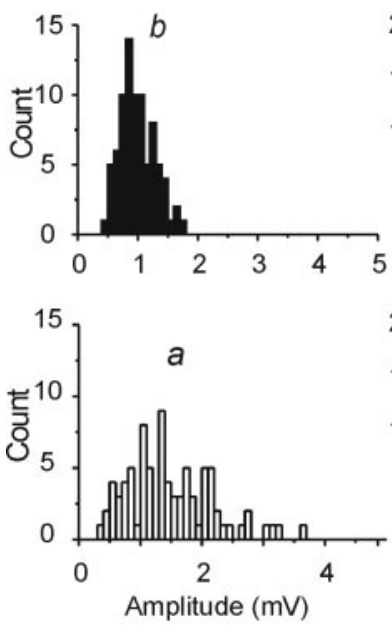

were depolarized via DC current to bring them near AP threshold. Under these conditions, TC stimuli evoked EPSPs that were either above threshold (Fig. 8 B1, first stimulus, bottom black trace; second stimulus, bottom gray trace) or below threshold (Fig. 8 B1, first stimulus, bottom gray trace; second stimulus, bottom black trace) for AP generation in the FS interneuron. A second depolarizing PSP (i.e., a uIPSP), with a peak latency of $\sim 6 \mathrm{~ms}$ after the FS spikes, was recorded in spiny neurons (Fig. 8 B1, top traces, large arrows). However, these late depolarizing IPSCs did not occur when the TC stimulus failed to evoke action potentials in the FS interneuron. In the cell pair shown in Figure $8 B 1$, the latency from the peak of the FS cell AP to the peak of the UIPSC was $6 \pm 1$ ms, whether the presynaptic AP was evoked by direct stimulation of the FS cell (Fig. 8A2,A3) or feedforward TC stimuli (Fig. $8 B 1$ ). Furthermore, we found that the amplitude of TC-mediated feedforward IPSPs in a given SS neuron was much larger when the TC stimulus evoked suprathreshold versus subthreshold responses in the FS neurons (Fig. 8B2,C1). The latency from the peak of APs in the presynaptic FS cell to the peak of the uIPSP $(\delta t)$ was $5.2 \pm 0.8 \mathrm{~ms}$ in six pairs of FS-SS cells. The inhibitory effects of the feedforward IPSPs could not be thoroughly examined under these conditions because of the depolarizing nature of the $\mathrm{GABA}_{\mathrm{A}}$ receptor-mediated IPSPs. However, the depolarizing IPSPs did reduce amplitude of the second APs in these neurons, presumably through a shunting action (data not shown).

To test the possibility that one or more FS neurons, firing synchronously with the recorded FS neuron, could contribute to the net feedforward inhibition in the recorded spiny cell, we analyzed the amplitude distribution of the feedforward IPSPs in the spiny neuron. There was a stepwise increase in the amplitude of the thalamocortical feedforward IPSPs and each step was similar in size to the FS-spiny uPSPs (Fig. 8C) $(n=3)$.

\section{Functional feedforward inhibition in spiny neurons}

When the intracellular pipette solution contained physiologically relevant $\mathrm{Cl}^{-}(6$ $\mathrm{mm}$; estimated $E_{\mathrm{Cl} / \mathrm{GABAA}},-77 \mathrm{mV}$ ), longlatency, presumed disynaptic IPSCs were of the UIPSP was $6 \pm 1 \mathrm{~ms}$ in the cell of Figure $8 A 3$ and averaged $6.5 \pm 1.4 \mathrm{~ms}$ for multiple trials in the three pairs. As shown schematically in Figure $8 \mathrm{~A}$, extracellular stimuli to TC afferents were used to elicit EPSPs in the three pairs of synaptically connected FS-SS neurons. For these experiments, the FS neurons evoked by TC stimuli in spiny neurons under voltage clamp (Fig. 9A1). Dual recordings were made from 15 pairs of spiny neurons in the same barrel. Excitatory synaptic coupling was present in 4 of these pairs (Fig. 10A1) and no functional connection could be found electrophysiologically in the remaining 11. Supramaximal 

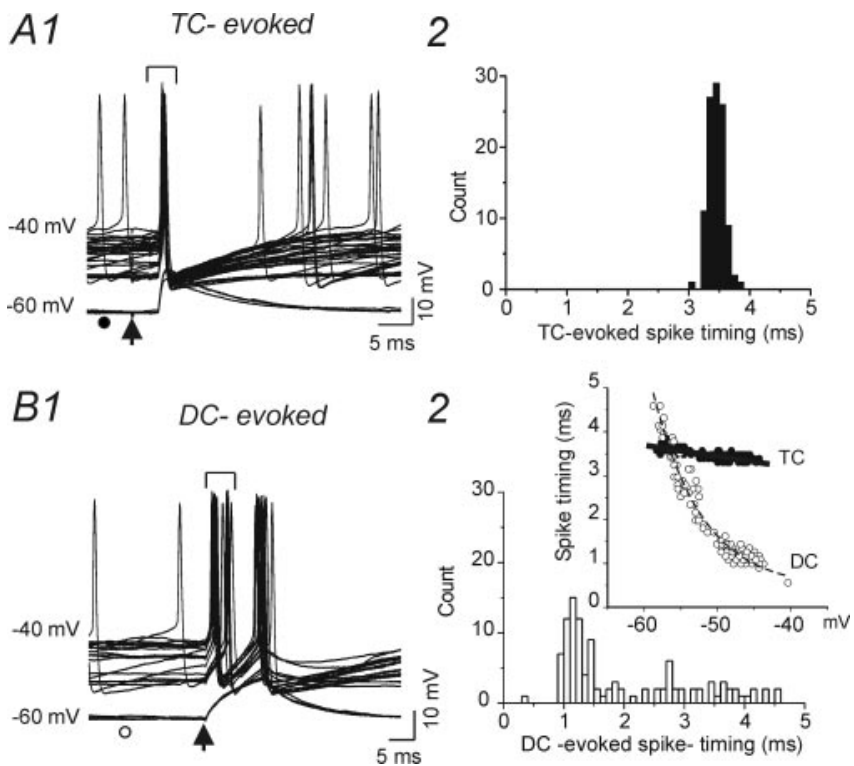

Figure 7. Thalamocortical-mediated spike synchronization in FS neurons. A1, Currentclamp recording from a $\mathrm{FS}$ interneuron showing TC-evoked subthreshold EPSPs at $V_{\text {hold }}$ of -60 $\mathrm{mV}$ (bottom traces) and short-latency APs triggered from the EPSP when $V_{\text {hold }}=-40 \mathrm{mV}$ (top traces). A2, Distribution of latencies from TC stimulus to AP peak in $-40 \mathrm{mV}$ traces of $\boldsymbol{A}$. $\boldsymbol{B}$, Current-clamp recording from $\mathrm{FS}$ interneuron of $\boldsymbol{A} \boldsymbol{1}$ showing spikes evoked by depolarizing current pulses $(+200 \mathrm{pA})$ at various $V_{\mathrm{m}}$ values ranging from -60 to $-40 \mathrm{mV}$. B2, Distribution of the latencies from onset of depolarizing pulse to AP peak with $V_{\text {hold }}$ at $-60 \mathrm{mV}$ for FS cell of $B 1$. Inset, Latencies to AP peak from TC stimulus (TC, filled circles) and onset of depolarizing current pulses (200 pA, $20 \mathrm{~ms}$; DC, open circles) at various $V_{\text {hold }}$ values. Arrows in $\boldsymbol{A} \mathbf{1}$ and $\boldsymbol{B} \mathbf{1}$ indicate onset of TC stimuli and DC pulses, respectively.

TC stimuli evoked multipeaked polysynaptic currents in 6 of the 15 spiny neuronal pairs (Fig. 9B1). These polysynaptic responses contained both inhibitory and excitatory synaptic events that had different reversal potentials under our recording conditions (data not shown). The outward IPSCs were highly synchronized in each pair of SS cells, as indicated by vertical lines in Figure 9B1 and the cross-correlation analysis of membrane currents in Figure $9 B 2$ (correlation coefficient, $0.38 \pm 0.5 ; n=6$; between the cells of each pair of spiny neurons). This was true whether or not the pair was synaptically coupled, suggesting that the cells received inhibitory synaptic inputs originating from a uniform population of interneurons with highly synchronized discharges. In five SS neurons, isolated TC-mediated putative disynaptic, feedforward IPSCs were recorded (i.e., those without a preceding monosynaptic EPSP) (Fig. 9A1,A2). In these neurons, the mean conductance of the feedforward IPSCs was $5.2 \pm 1.4 \mathrm{nS}$, which was similar in magnitude to both the IPSC component of mixed PSCs $(5.8 \pm 0.8 \mathrm{nS} ; n=7$ ) (Fig. $10 \mathrm{B2}$, inset) and that of FS neuron-mediated uIPSCs (Fig. $3 B$ ). In each of the five $S S$ neurons with isolated IPSCs, we found that the feedforward IPSCs were evoked in an all-or-none manner, suggesting that only one or a few FS neurons were responsible (Fig. 9A2).

To further explore the functional consequences of the TCmediated feedforward IPSPs, we recorded from pairs of spiny neurons either both located in the same barrel or each in a different barrel. Current-clamp recordings from pairs of connected spiny neurons in the same barrel showed that TC stimuli evoked monosynaptic EPSPs followed immediately by feedforward hyperpolarizing IPSPs in the connected pairs (Fig. 10 A2). The time course and amplitude of the feedforward IPSPs were similar in the cells of each pair, suggesting that the inhibitory input arose from a small homogeneous population of interneurons. In

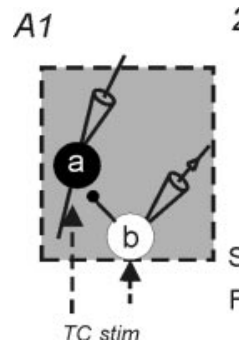

$28 \mathrm{t}$

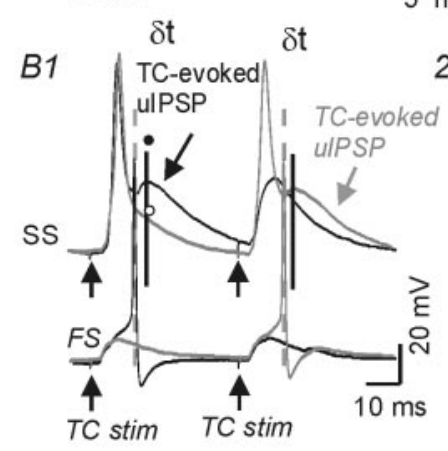

2

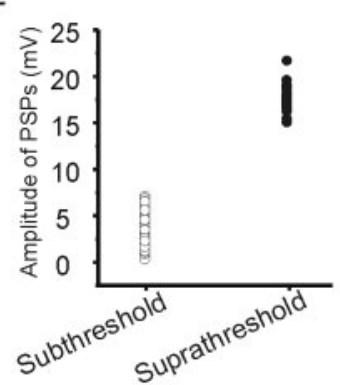

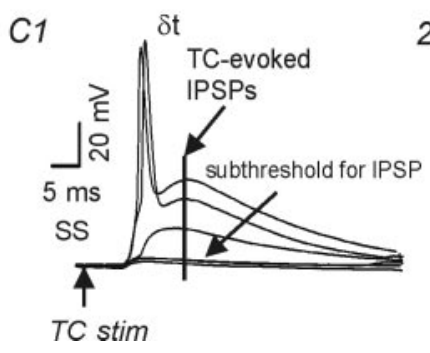

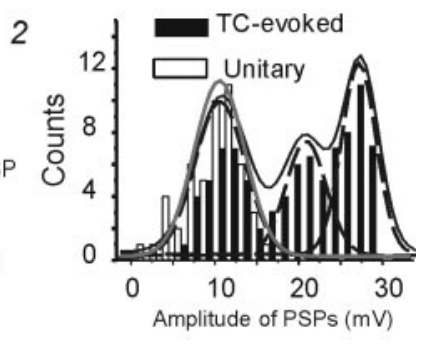

Figure 8. Unitary disynaptic feedforward inhibition from FS interneurons onto spiny stellate neurons. A1, Diagram showing sites of paired recordings from a synaptically connected FS neuron (b) and an SS cell (a) in the same barrel structure (gray square). Extracellular stimuli in the thalamocortical radiation (dotted arrows) excited cells $a$ and $b$ and evoked APs in cell $b$ that elicited feedforward uIPSCs in cell a. A2, Single action potential (bottom gray trace) in presynaptic FS neuron evoked a uIPSP (top black trace) in a postsynaptic SS cell. Vertical dashed and dark lines mark the peaks of the action potential and uIPSP, respectively. $\delta t$, Time from peak of presynaptic action potential to the peak of ulPSP. $E_{\mathrm{Cl}} \approx-32 \mathrm{mV}$. A3, Histogram showing $\delta t$ distribution for the FS-SS pair. The long and variable latency to the IPSP peak is attributable to the slow rising slope of the uIPSP in this current-clamp recording. $\boldsymbol{B} 1$, Current-clamp recording from the cell pair of $\boldsymbol{A}$ showing responses evoked by two consecutive pairs of TC stimuli. In the first trial (black traces of $\mathrm{FS}$ and $\mathrm{SS}$ recordings), the first, but not the second TC stimulus, evoked APs in both the SS (top trace) and FS neuron (bottom). The peak of a depolarizing PSP in the SS cell (solid line and arrow, TC-evoked uIPSP) occurred $\sim 6 \mathrm{~ms}$ after the peak of the FS action potential (dashed line). In the second trial (gray traces), the first TC stimulus evoked an AP in the SS, but not the FS cell, whereas the second stimulus evoked APs in both cells and a depolarizing PSP $\sim 6 \mathrm{~ms}$ after the FS cell action potential. B2, Distribution of amplitudes for the TC-evoked feedforward PSPs in the SS neuron of $\boldsymbol{B} 1$. The two groups were selected based on whether TC stimulus evoked responses that were subthreshold (open circles) or suprathreshold (filled circles) for APs in the FS neuron. $C$, Representative recording from a spiny neuron showing that graded TC stimulation $(100-200 \mu \mathrm{A})$ could evoke stepwise increases in feedforward inhibition. The weakest stimuli evoked only monosynaptic EPSPs that were subthreshold for APs and IPSPs (bottom 2 traces). As the stimulus intensity was increased, both early monosynaptic and late disynaptic responses were augmented. The late response, a presumed feedforward depolarizing IPSP, showed stepwise increases in amplitude (top 2 traces). $\mathbf{C}$, Amplitude distributions of TC-evoked late IPSPs from experiment in C1 (black bars) and uIPSPs recorded in the same neuron (white bars). The TC-IPSP responses were fitted by the sum (black line) of three individual Gaussian curves (dashed lines), with mean amplitudes of 10.2, 22, and $26 \mathrm{mV}$. A single Gaussian distribution (gray line; mean, $10.2 \mathrm{mV}$ ) was fitted to the ulPSP distribution. stim, Stimulus.

$\sim 60 \%$ (22 of 37 ) of spiny neurons, the TC-evoked EPSPs triggered APs followed by disynaptic IPSPs, whereas in the remaining $40 \%$ ( 15 of 37), the TC stimulus evoked subthreshold EPSPs (Fig. $10 A 2)$. Feedforward GABAergic IPSPs were evoked in $\sim 80 \%$ of 
A1 Voltage-clamp, $[\mathrm{Cl}]=6 \mathrm{mM}$

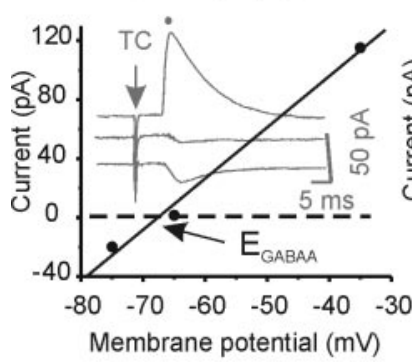

B1

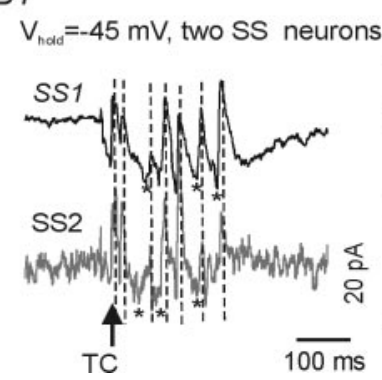

2

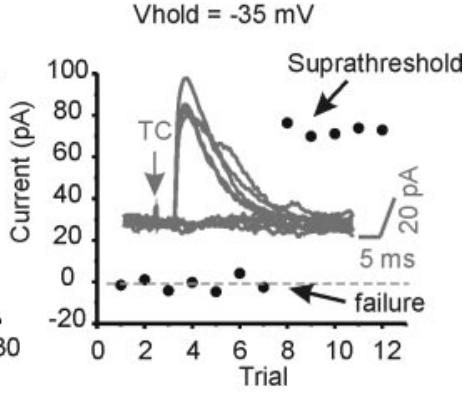

2

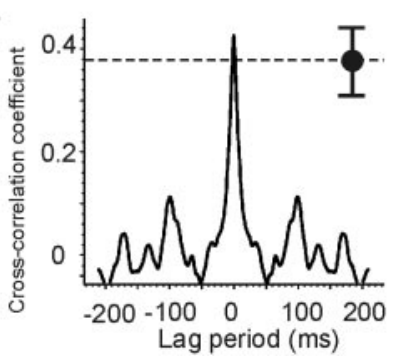

Figure 9. TC-evoked inhibitory inputs onto spiny neurons in layer IV barrel. A1, Voltageclamp recordings of TC-evoked putative disynaptic IPSCs. Plot of peak IPSC amplitude versus $V_{\text {hold }}\left(-75,-65,-35 \mathrm{mV}\right.$; solid circles and line) in an $\mathrm{SS}$ neuron. Arrow, Estimated $E_{\mathrm{GABAA}}=$ $-68 \mathrm{mV}$. Dashed line, Zero current. A2, Subthreshold and suprathreshold TC stimulus-evoked putative disynaptic all-or-none IPSCs in another SS neuron ( $\left.V_{\text {hold }}=-35 \mathrm{mV} ; E_{C I}=-68 \mathrm{mV}\right)$. $B 1$, Voltage-clamp recordings from two $S S$ neurons in the same barrel showing polysynaptic inhibitory (outward) and excitatory (inward) currents evoked by a strong $\mathrm{TC}$ stimulus $\left(V_{\text {hold }}=\right.$ $\left.-45 \mathrm{mV} ; E_{\mathrm{Cl}}=-68 \mathrm{mV}\right)$. Asterisks mark the occurrence of EPSCs and vertical dashed lines mark peaks of IPSPs that are approximately synchronous in the two cells. B2, Cross-correlation analysis of the polysynaptic responses in cells $S S 1$ and $S S 2$ of $\boldsymbol{B} 1$. Filled black circle, Mean cross-correlation coefficient at time 0 obtained from trials in six similar spiny neuronal pairs.

all spiny neurons ( 30 of 37 ). In six simultaneous recordings from two SS neurons located in different barrels (Fig. 10B1) $(n=6)$, thalamocortical stimulation evoked a suprathreshold response in one spiny neuron (Fig. 10 B1, SS1) but only a putative feedforward IPSP (Fig. 10 B1, SS2, middle trace) $(n=3)$, no response (Fig. 10 B1, SS2, bottom trace), or subthreshold EPSP followed by strong feedforward IPSP (data not shown) $(n=1)$, in the other SS cell. The relative absence of TC EPSPs in SS neurons of the adjacent barrel suggests that the TC stimulus mainly activated a single barrel and that TC-mediated feedforward inhibition, possibly mediated by the sparse FS cell axons that do extend beyond the barrel structure (Fig. 1, compare interneurons 1 and 2), can modulate the excitability of spiny neurons located in different barrels.

In summary, paired recordings from monosynaptically connected FS-spiny neurons and spiny-spiny neurons show that highly reliable feedforward IPSPs are elicited by TC stimulation. These IPSCs are likely mediated by fast-spiking interneurons (Figs. 8, 9) (see Discussion).

\section{Discussion}

We have examined functional aspects of microcircuits in rat sensory cortex using a thalamocortical slice preparation. Factors to consider regarding the interpretation of results from in vitro studies include developmental stage, locations of stimulating electrodes, differences between electrically evoked and more nat-

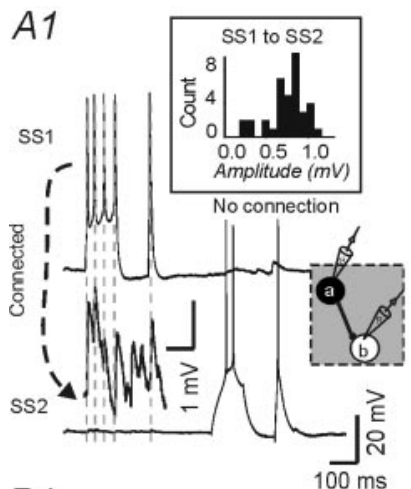

2

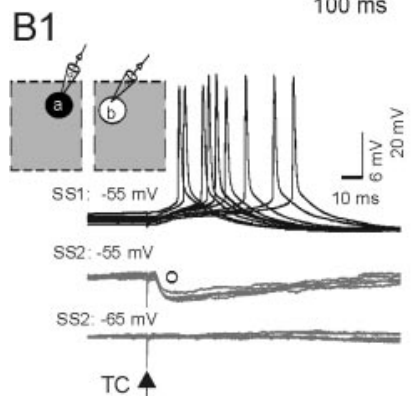

Figure 10. Functional feedforward inhibition in layer IV evoked by thalamocortical afferents. A1, Current-clamp recording from an SS-SS cell pair in the same barrel. Depolarizing current pulse evokes a train of APs in SS1 (presynaptic cell, top trace) and a train of uEPSPs in SS2 (bottom 2 traces). Segment above bottom trace shows first part of SS2 trace at $20 \times$ higher gain. Inset, Amplitude histogram for the uEPSPs in SS2. A2, TC stimuli evoke feedforward inhibition onto spiny neurons. Simultaneous current-clamp recordings from the SS pair of $\boldsymbol{A}$ showing responses to a single TC stimulus ( 7 trials overlaid). Arrow and dotted vertical line, Time of TC stimulus. Dashed lines, $V_{\text {hold }}=-50 \mathrm{mV}$. Note that the stimuli evoked EPSPs (black arrows) followed by disynaptic feedforward IPSPs (arrows) in both SS cells. B1, Simultaneous current-clamp recordings from two spiny neurons, located in separate barrels, showing responses to a single TC stimulus (9 trials overlaid). TC stimuli evoke suprathreshold EPSPs in one spiny neuron (SS1, top trace) but feedforward inhibition onto the other spiny neuron (SS2, middle trace) located in an adjacent barrel. The IPSP in SS2 was abolished at the reversal potential for the response (bottom trace). Membrane potential given above each set of traces. $E_{\mathrm{Cl}}=-68 \mathrm{mV}$. B2, Relationship between resting potential and the amplitude of the feedforward TC evoked disynaptic IPSPs in SS2 of $\boldsymbol{B}$ 1. Estimated $E_{\text {IPSP }}-65 \mathrm{mV}$. Inset, Conductance of TC-mediated disynaptic IPSC in spiny neurons. Circles indicate values from individual cells ( $n=$ $7)$, whereas the dark square is the average response $\left(V_{\text {hold }}=-40 \mathrm{mV}\right.$; estimated $E_{\mathrm{CI}}$ IPSP $_{\text {GABAA }}$ $-68 \mathrm{mV})$.

ural sensory inputs, selection of neurons, and disruption of interlaminar and/or intralaminar connectivity. Despite these potential limitations, several consistent findings emerge with respect to thalamocortical feedforward inhibition in layer IV of barrel cortex: (1) the conductance of inhibitory synaptic connections from FS, but not RSNP interneurons, is up to 10 times greater than that of excitatory synaptic input from single spiny neurons; (2) thalamocortical inputs reliably activate FS interneurons; (3) spiny neurons receive strong local inhibition that primarily arises from a few interneurons; and (4) powerful unitary feedforward inhibition onto spiny cells can be provided by single fast-spiking interneurons.

\section{Interaction between inhibitory and excitatory networks}

Diverse interneurons exist in rodent layer IV barrel field (Simons, 1978; Keller and White, 1987; Porter et al., 2001). These are of nonspiny, multipolar, and bi-tufted varieties, and some of them have beaded dendrites (Keller and White, 1987). These interneurons can also be classified as RSNP, IB (intrinsically bursting), or 
FS cells (Agmon and Connors, 1992; Kawaguchi and Kubota, 1993; Kim et al., 1995; Castro-Alamancos and Connors, 1997; Zhu and Connors, 1999; Porter et al., 2001; Beierlein et al., 2003). Little is known regarding the form of inhibition arising from each interneuron type onto spiny (glutamatergic) neurons. These diverse types of interneurons all receive thalamocortical innervation (Simons, 1978; Keller and White, 1987; Porter et al., 2001), but our results indicate that FS interneurons are the predominant subgroup underlying feedforward inhibition. In contrast, RSNP cells provide only weak GABAergic inputs. These results are consistent with those obtained in layer $\mathrm{V}$ pyramidal neurons, in which FS cell uIPSCs were found to be much stronger than those originating from low-threshold spiking interneurons (Xiang et al., 2002).

The FS interneurons of this study were likely nest basket cells and small basket cells (Martin et al., 1983; Keller and White, 1987; Hendry et al., 1989; Tamas et al., 1997; Wang et al., 2002), whereas the glutamatergic neurons were spiny stellate cells and star pyramidal neurons (Figs. 1, 4). In the barrel cortex, the organization and physiology of subtypes of GABAergic neurons are relatively stereotyped (Silberberg et al., 2002). Our results are consistent with this. For example, all FS interneurons are located near the center and lower barrel, whereas SS cells are located near the later borders of the barrel (Fig. 1) (Woolsey and Van der Loos, 1970; Keller and White, 1987). IPSCs from two types of interneurons (FS and RSNP) onto SS cells are distinct, whereas synaptic connections between neurons of a group (FS to FS, RSNP to RSNP, spiny to spiny) are similar, at least in terms of strength. Previous studies have shown that SS cells form reciprocal connections within the same barrel (Egger et al., 1999; Feldmeyer et al., 1999, 2002; Petersen and Sakmann, 2000), as do layer IV star pyramids (Schubert et al., 2003), yet the properties of the connections between star pyramids have not been reported. We found that excitatory synaptic connections between spiny stellate cells and star pyramidal neurons are similar to those reported previously for other spiny neurons. Although we did not characterize the conductances underlying layer IV uEPSPs in detail, we found that the unitary excitatory synaptic responses were generally similar among different targets (SS, RSNP, and FS) (Tables 2, 3) and consistent with previous results (Angulo et al., 1999; Feldmeyer et al., 1999, 2002; Holmgren et al., 2003).

\section{Thalamocortical feedforward inhibition in layer IV}

As an initial target of thalamocortical afferents, layer IV interneurons serve important roles in sensory processing. However, the exact roles of interneuron subtypes are not clear. Thalamocortical afferents are known to have a higher probability of evoking action potentials in RSNP and FS interneurons than in excitatory neurons (Porter et al., 2001), in part because of stronger monosynaptic TC EPSPs onto interneurons (Gibson et al., 1999). Our results are consistent with these previous reports. Results of in vivo studies suggest that suspected inhibitory interneurons (SINs), likely FS cells, mediate TC feedforward inhibition in cortex (Swadlow, 2002, 2003). To do so, these interneurons must faithfully respond to TC input at low threshold and provide reliable monosynaptic inhibition onto spiny neurons. Our data from paired FS-SS recordings demonstrate significant feedforward inhibition only when TC stimuli were suprathreshold for action potential generation in FS interneurons, and that feedforward IPSPs occurred with short peak latency ( $\sim 6 \mathrm{~ms}$ ) (Fig. 8).

Several lines of evidence indicate that FS neurons dominate feedforward inhibition. (1) Feedforward inhibitory strength is similar to that produced by one or a few FS neuron uIPSPs (Fig.
$10 B 2)$. (2) Highly synchronized feedforward inhibition was evident in multiple spiny neurons (Figs. 9B, 10A2). (3) Thalamocortical inputs evoked synchronized APs in FS but not RSNP neurons (Figs. 7, 10). (4) Feedforward inhibition in SS cells was quantal (Fig. 9A2), suggesting that it was mediated by one or a few neurons.

What role might RSNP neurons play in feedforward inhibition? Based on the weak output of RSNP neurons onto spiny neurons and lack of synchronous TC activation, under static conditions these neurons are unlikely to provide significant feedforward inhibition. However, different classes of interneurons form electrically coupled networks (Gibson et al., 1999; Beierlein et al., 2003; Blatow et al., 2003), and recently, non-FS interneurons (Gibson et al., 1999; Deans et al., 2001; Blatow et al., 2003) were shown to generate rhythmic synchronous theta frequency oscillations after cholinergic or glutamatergic activation. Such rhythmic inhibition can provide synchronization of spiny cell output and may promote coordination of sensory and motor cortices during rodent exploratory behavior and vibrissa whisking. Additional experiments combining in vivo recordings and neuroanatomical techniques will be needed to explore the role of RSNP neurons in such behaviors.

\section{Inhibition and integration in thalamocortical microcircuits of rat barrel cortex}

The majority ( $\sim 70-90 \%)$ of neurons within layer IV barrels form a reciprocal excitatory network, and are targets for TC inputs (Egger et al., 1999; Feldmeyer et al., 1999, 2002; Petersen and Sakmann, 2000). In contrast, interneurons represent a minority $(10-30 \%)$ of neurons within the barrel cortex (Simons, 1978; Keller and White, 1987; Micheva and Beaulieu, 1995). In order for precise registration of sensory information without runaway recurrent excitation, excitation and inhibition must be balanced (Chagnac-Amitai and Connors, 1989). How does inhibition supplied by a limited number of interneurons provide the necessary control? Our quantitative analysis of unitary inhibitory and excitatory synaptic events provides information relevant to this issue.

The conductance of uIPSCs from FS interneurons onto spiny neurons is $\sim 10$-fold greater than that of uEPSCs onto any cell type. This difference, together with rapid feedforward inhibition (Figs. 9, 10), serves to counteract the convergent cortical excitation from spiny neurons. Cross-correlation analysis of TCevoked polysynaptic responses from unconnected spiny neurons in the same barrel (Fig. 9B) suggests that these cells receive inhibition from a common group of interneurons. Feedforward inhibition, presumably provided by the FS interneurons, limits the TC-mediated excitation of spiny neurons and reduces the likelihood that disynaptic reciprocal excitation will occur (Fig. 10 A), particularly when TC input is weak (Swadlow, 2002, 2003). Our results show that FS cell activation can result in inhibition of spiking in spiny neurons located in both the same and in adjacent barrels (Fig. $10 \mathrm{~B}$ ). This finding supports the idea that FS neurons are involved in modifying receptive field properties in barrel cortices. In the auditory cortex, cortical inhibition serves to increase temporal precision during sound processing, via feedforward inhibition that occurs precisely after pyramidal neuron APs (Wehr and Zador, 2003). However, there are no differences in receptive fields between excitatory neurons and inhibitory neurons in auditory cortex. This finding is different from our results, in which feedforward inhibition controls both the temporal precision (Figs. $8 B, 10 A$ ) and likely the receptive field (Fig. 10B) (Bruno and Simons, 2002). 
Our results show that the strength of feedforward IPSCs on excitatory neurons in the barrel is, on average, similar to that of the uIPSP from a single FS neuron (Fig. 10 B2). We occasionally recorded stepwise increases in the amplitude of the thalamocortical feedforward IPSPs such that each step was similar in amplitude to that of an FS-spiny neuron uIPSP (Fig. 8 B2). These findings suggest that small numbers of FS cells, or even single FS cells, can evoke effective inhibition of spiny neurons in the barrel. Recordings from pairs of adjacent spiny neurons show that they receive highly synchronized IPSPs (Fig. 9B2), likely resulting from synchronous TC activation of groups of FS cells that are electrically coupled within the FS interneuronal network (Gibson et al., 1999). More direct demonstration of the role of electrical coupling in mediating TC feedforward inhibition will require triple recordings from pairs of electrically coupled FS neurons and single SS neurons that are all activated by thalamocortical inputs.

\section{References}

Agmon A, Connors BW (1991) Thalamocortical responses of mouse somatosensory (barrel) cortex in vitro. Neuroscience 41:365-379.

Agmon A, Connors BW (1992) Correlation between intrinsic firing patterns and thalamocortical synaptic responses of neurons in mouse barrel cortex. J Neurosci 12:319-329.

Agmon A, Yang LT, Jones EG, O’Dowd DK (1995) Topological precision in the thalamic projection to neonatal mouse barrel cortex. J Neurosci 15:549-561.

Agmon A, Hollrigel G, Odowd DK (1996) Functional GABAergic synaptic connection in neonatal mouse barrel cortex. J Neurosci 16:4684-4695.

Angulo MC, Rossier J, Audinat E (1999) Postsynaptic glutamate receptors and integrative properties of fast-spiking interneurons in the rat neocortex. J Neurophysiol 82:1295-1302.

Beierlein M, Connors BW (2002) Short-term dynamics of thalamocortical and intracortical synapses onto layer 6 neurons in neocortex. J Neurophysiol 88:1924-1932.

Beierlein M, Gibson JR, Connors BW (2000) A network of electrically coupled interneurons drives synchronized inhibition in neocortex. Nat Neurosci 3:904-910.

Beierlein M, Fall CP, Rinzel J, Yuste R (2002) Thalamocortical bursts trigger recurrent activity in neocortical networks: layer 4 as a frequencydependent gate. J Neurosci 22:9885-9894.

Beierlein M, Gibson JR, Connors BW (2003) Two dynamically distinct inhibitory networks in layer 4 of the neocortex. J Neurophysiol 90:2987-3000.

Blatow M, Rozov A, Katona I, Hormuzdi SG, Meyer AH, Whittington MA, Caputi A, Monyer H (2003) A novel network of multipolar bursting interneurons generates theta frequency oscillations in neocortex. Neuron 38:805-817.

Brecht M, Sakmann B (2002) Whisker maps of neuronal subclasses of the rat ventral posterior medial thalamus, identified by whole-cell voltage recording and morphological reconstruction. J Physiol (Lond) 538:495-515.

Bruno RM, Simons DJ (2002) Feedforward mechanisms of excitatory and inhibitory cortical receptive fields. J Neurosci 22:10966-10975.

Castro-Alamancos MA, Connors BW (1997) Thalamocortical synapses. Prog Neurobiol 51:581-606.

Chagnac-Amitai Y, Connors BW (1989) Synchronized excitation and inhibition driven by intrinsically bursting neurons in neocortex. J Neurophysiol 62:1149-1162.

Deans MR, Gibson JR, Sellitto C, Connors BW, Paul DL (2001) Synchronous activity of inhibitory networks in neocortex requires electrical synapses containing connexin36. J Physiol (Lond) 31:477-485.

Egger V, Feldmeyer D, Sakmann B (1999) Coincidence detection and changes of synaptic efficacy in spiny stellate neurons in rat barrel cortex. Nat Neurosci 2:1098-1105.

Feldman DE, Nicoll RA, Malenka RC (1999) Synaptic plasticity at thalamocortical synapses in developing rat somatosensory cortex: LTP, LTD, and silent synapses. J Neurobiol 41:92-101.

Feldmeyer D, Egger V, Lubke J, Sakmann B (1999) Reliable synaptic con- nections between pairs of excitatory layer 4 neurones within a single "barrel" of developing rat somatosensory cortex. J Physiol (Lond) 521:169-190.

Feldmeyer D, Lubke J, Silver RA, Sakmann B (2002) Synaptic connections between layer 4 spiny neurone-layer 2/3 pyramidal cell pairs in juvenile rat barrel cortex: physiology and anatomy of interlaminar signalling within a cortical column. J Physiol (Lond) 538:803-822.

Froemke RC, Dan Y (2002) Spike-timing-dependent synaptic modification induced by natural spike trains. Nature 416:433-438.

Gibson JR, Beierlein M, Connors BW (1999) Two networks of electrically coupled inhibitory neurons in neocortex. Nature 402:75-79.

Gil Z, Connors BW, Amitai Y (1999) Efficacy of thalamocortical and intracortical synaptic connections: quanta, innervation, and reliability. Neuron 23:385-397.

Gupta A, Wang Y, Markram H (2000) Organizing principles for a diversity of GABAergic interneurons and synapses in the neocortex. Science 287:273-278.

Hendry SH, Jones EG, Emson PC, Lawson DE, Heizmann CW, Streit P (1989) Two classes of cortical GABA neurons defined by differential calcium binding protein immunoreactivities. Exp Brain Res 76:467-472.

Holmgren C, Harkany T, Svennenfors B, Zilberter Y (2003) Pyramidal cell communication within local networks in layer $2 / 3$ of rat neocortex. J Physiol (Lond) 551:139-153.

Kawaguchi Y, Kubota Y (1993) Correlation of physiological subgroupings of nonpyramidal cells with parvalbumin- and calbindinD28kimmunoreactive neurons in layer $\mathrm{V}$ of rat frontal cortex. J Neurophysiol 70:387-396.

Keller A, White EL (1987) Synaptic organization of GABAergic neurons in the mouse SmI cortex. J Comp Neurol 262:1-12.

Kim HG, Fox K, Connors BW (1995) Properties of excitatory synaptic events in neurons of primary somatosensory cortex of neonatal rats. Cereb Cortex 5:148-157.

Martin KA, Somogyi P, Whitteridge D (1983) Physiological and morphological properties of identified basket cells in the cat's visual cortex. Exp Brain Res 50:193-200.

Micheva KD, Beaulieu C (1995) Postnatal development of GABA neurons in the rat somatosensory barrel cortex: a quantitative study. Eur J Neurosci 7:419-430.

Nelson SB (1991) Temporal interactions in the cat visual-system. III. Pharmacological studies of cortical suppression suggest a presynaptic mechanism. J Neurosci 11:369-380.

Nelson SB, Sjostrom PJ, Turrigiano GG (2002) Rate and timing in cortical synaptic plasticity. Philos Trans R Soc Lond B Biol Sci 357:1851-1857.

Petersen CCH, Sakmann B (2000) The excitatory neuronal network of rat layer 4 barrel cortex. J Neurosci 20:7579-7586.

Porter JT, Johnson CK, Agmon A (2001) Diverse types of interneurons generate thalamus-evoked feedforward inhibition in the mouse barrel cortex. J Neurosci 21:2699-2710.

Schubert D, Kotter R, Zilles K, Luhmann HJ, Staiger JF (2003) Cell typespecific circuits of cortical layer IV spiny neurons. J Neurosci 23:2961-2970.

Silberberg G, Gupta A, Markram H (2002) Stereotypy in neocortical microcircuits. Trends Neurosci 25:227-230.

Simons DJ (1978) Response properties of vibrissa units in rat SI somatosensory neocortex. J Neurophysiol 41:798-820.

Simons DJ, Woolsey TA (1979) Functional organization in mouse barrel cortex. Brain Res 165:327-332.

Simons DJ, Durham D, Woolsey TA (1984) Functional organization of mouse and rat SmI barrel cortex following vibrissal damage on different postnatal days. Somatosens Res 1:207-245.

Somogyi P, Tamas G, Lujan R, Buhl EH (1998) Salient features of synaptic organisation in the cerebral cortex. Brain Res Brain Res Rev 26:113-135.

Swadlow HA (2002) Thalamocortical control of feed-forward inhibition in awake somatosensory "barrel" cortex. Philos Trans R Soc Lond B Biol Sci 357:1717-1727.

Swadlow HA (2003) Fast-spike interneurons and feedforward inhibition in awake sensory neocortex. Cereb Cortex 13:25-32.

Tamas G, Buhl EH, Somogyi P (1997) Fast IPSPs elicited via multiple synaptic release sites by different types of GABAergic neurone in the cat visual cortex. J Physiol (Lond) 500:715-738. 
Vidyasagar TR, Pei X, Volgushev M (1996) Multiple mechanisms underlying the orientation selectivity of visual cortical neurones. Trends Neurosci 19:272-277.

Wang Y, Gupta A, Toledo-Rodriguez M, Wu CZ, Markram H (2002) Anatomical, physiological, molecular and circuit properties of nest basket cells in the developing somatosensory cortex. Cereb Cortex 12:395-410.

Wehr M, Zador AM (2003) Balanced inhibition underlies tuning and sharpens spike timing in auditory cortex. Nature 426:442-446.

White EL, Peters A (1993) Cortical modules in the posteromedial barrel subfield (Sml) of the mouse. J Comp Neurol 334:86-96.

White EL, Rock MP (1980) Three-dimensional aspects and synaptic relationships of a Golgi- impregnated spiny stellate cell reconstructed from serial thin sections. J Neurocytol 9:615-636.

White EL, Amitai Y, Gutnick MJ (1993) A novel approach to correlative studies of neuronal structure and function. Isr J Med Sci 29:549-555.
Wong-Riley M (1979) Changes in the visual system of monocularly sutured or enucleated cats demonstrable with cytochrome oxidase histochemistry. Brain Res 171:11-28.

Woolsey TA, Van der Loos H (1970) The structural organization of layer IV in the somatosensory region (SI) of mouse cerebral cortex. The description of a cortical field composed of discrete cytoarchitectonic units. Brain Res 17:205-242.

Woolsey TA, Dierker ML, Wann DF (1975) Mouse SmI cortex: qualitative and quantitative classification of Golgi-impregnated barrel neurons. Proc Natl Acad Sci USA 72:2165-2169.

Xiang Z, Huguenard JR, Prince DA (2002) Synaptic inhibition of pyramidal cells evoked by different interneuronal subtypes in layer $\mathrm{V}$ of rat visual cortex. J Neurophysiol 88:740-750.

Zhu JJ, Connors BW (1999) Intrinsic firing patterns and whisker-evoked synaptic responses of neurons in the rat barrel cortex. J Neurophysiol 81:1171-1183. 